\title{
EDITORIAL
}

\section{Divulgación científica y la biodiversidad}

\section{Leonardo Romero}

\section{Editor Jefe}

Los Bosques relictos del Noroeste de Perú y Suroeste de Ecuador es el primer número especial de la Revista Peruana de Biología, y empezamos esta serie con el tema de la biodiversidad y la conservación de un ecosistema de extrema importancia tanto por la biodiversidad que albergan, sus especies endémicas y las cuencas hidrográficas que protegen, como por las evidentes amenazas a que es sometido. Con este número especial la Revista Peruana de Biología y su casa editora, la Universidad Nacional Mayor de San Marcos, quiere dar forma a la misión de documentar el conocimiento biológico que se genera en nuestro país, misión que redundará en beneficio de nuestra sociedad y el uso sostenible de la biodiversidad.

La difusión de las investigaciones en los países en desarrollo se ven limitadas por diversos motivos. Por un lado la falta de medios adecuados, por otro la competencia por un mercado limitado, exigente y que en los últimos 40 años ha convertido a la literatura científica en un objeto de lujo. Los investigadores de países en desarrollo, no solamente han visto limitadas las posibilidades en la difusión de sus investigaciones, sino también el público receptor, académico y no-académico, la sociedad en su totalidad, la cual ignora en la mayoría de los casos las investigaciones realizadas en su territorio.

Se conoce que las investigaciones que se realizan en ocho países desarrollados (encabezados por USA, Reino Unido y Japón) es aproximadamente el $80 \%$ del total de las citaciones en trabajos publicados en las denominadas revistas internacionales, mientras que solamente 160 países aportan el 2,5\%. A esto se suma que el $80 \%$ de la población mundial esta limitada en su acceso al conocimiento y a las investigaciones que genera por los costos de las denominadas publicaciones internacionales ${ }^{1}$. Con este número especial queremos reforzar el compromiso de proporcionar documentación de acceso libre para el conocimiento de la biodiversidad dentro de la filosofía del Open Access ${ }^{2}$.

La humanidad vive en un escenario en el cual las amenazas a la biodiversidad en sus diferentes niveles se vienen incrementando de manera más conspicua, por ejemplo la Unión Mundial para la Naturaleza (IUCN) estima que actualmente hay 7000 especies animales en situación de peligro, mientras que el número de las vegetales en la misma situación se acerca a las $8000^{3}$; así también en La Evaluación de los Ecosistemas del Milenio ${ }^{4}$ los expertos confirman la degradación de 15 funciones de ecosistemas de un total de 24 . En este escenario las publicaciones científicas juegan un papel importante en la documentación académica de los diferentes elementos, procesos y funciones de la biodiversidad. Estos documentos permitirán dar la base necesaria a los políticos y tomadores de decisiones para proponer los mecanismos para revertir este panorama sombrío.

\section{Lima, 8 de diciembre 2005}

\footnotetext{
${ }^{1}$ Leslie Chan, Barbara Kirsop and Subbiah Arunachalam. 2005. Open Access Archiving: the fast track to building research capacity in developing countries. SciDev.Net http://www.scidev.net. Acceso 20 nov 2005.

${ }^{2}$ http://www.eprints.org/openaccess/

${ }^{3}$ IUCN. 2004. The IUCN Red List of Threatened Species. (http://www.iucnredlist.org/). Acceso 2 nov. 2004

${ }^{4}$ Programa de las Naciones Unidas para el Medio Ambiente. 2005. Borrador de Documento de Información: Evaluación de los Ecosistemas del Milenio. UNEP/LAC-IGWG.XV/13.A. Reunión Preparatoria de Expertos, 31 de octubre al 2 de noviembre de 2005.
} 